\title{
Care needs among the dependent population in Spain: an empirical approach
}

\author{
J. Garcés ${ }^{1} \mathrm{PhD}, \mathrm{F}$. Ródenas ${ }^{1} \mathrm{PhD}$ and V. Sanjosé ${ }^{2} \mathrm{PhD}$ \\ 'Poliwelfare' Research Unit, Department of Social Work and Social Services, Universitat de València and 'Poliwelfare' \\ Research Unit, Department of Science Education, Universitat de València, València, Spain
}

\author{
Correspondence \\ Jorge Garcés \\ Universitat de València \\ Facultad de Ciencias Sociales \\ Departamento de Trabajo Social y \\ Servicios Sociales \\ Avda. De los Naranjos \\ s/n. 46022 \\ Valencia \\ Spain \\ E-mail: jordi.garces@uv.es
}

\begin{abstract}
The objective of the present paper was to identify the profile and needs of social and healthcare users in Spain who required long-term care. To achieve this goal, an extensive empirical study was carried out in 2001 of a typical southern European region: the Valencia Autonomous Region in Spain. The method used was a questionnaire-based survey. The data collection instrument was a questionnaire comprising 119 questions grouped into seven sections: social and demographic data; clinical diagnosis and treatment; living environment; degree of dependence in activities of daily living (ADLs); cognitive state; social support; and the social, demographic and attendance data of the carer, if available. The sampling was carried out in two strata, i.e. social and healthcare: first, the authors randomly selected the centres and services as sampling points, and then they randomly selected the subjects. A total of 1265 people were interviewed. The results show different care profiles: users aged under 65 years were mostly mentally ill and/or drug users requiring short- and medium-term care from the health services, while those aged over 65 years had chronic illnesses for which they were actively receiving treatment, were functionally dependent for ADLs, and were normally receiving social care that basically provided company and resolved functional limitations.
\end{abstract}

Keywords: care needs, dependence, health care, long-term care, social care, social sustainability

Accepted for publication 5 April 2004

\section{Introduction}

Welfare studies in different European countries have revealed similar social and economic problems (Gustafsson \& Klevmarken 1989, Munday 1993, Munday \& Ely 1996, Organisation for Economic Cooperation and Development 1996, 1998, Bonoli et al. 2000, Kautto et al. 2001). Hence, welfare problems such as the rise in the 'pensioner ratio' and the increase in demand for long-term care (Garcés 2000) are beginning to be perceived as supra-national issues. The common phenomenon of an ageing population in Europe signifies a major challenge for the financial systems (Economic Policy Committee 2001, 2002), and the social and healthcare systems of each country (DirectorateGeneral for Economic and Financial Affairs 2002a,b).
Studies designed to quantify care needs make an important contribution to policy development, service planning and care provision. The present paper describes the results of a study carried out in 2001 in a typical Mediterranean region of Spain, the Valencia Autonomous Region. The purpose of this study was to assess the social and healthcare needs of patients using institutional facilities and care services.

\section{Subjects and methods}

There were 238718 people in the Valencia Autonomous Region who were dependent on help in order to carry out activities of daily living (ADLs) (Garcés et al. 2002), representing $5.9 \%$ of the total population, a somewhat lower proportion than in Spain as a whole, for which 
the figure is 7\% (Instituto de Migraciones y Servicios Sociales 2000).

The sample was drawn from the main types of social and health services which are available in Valencia. Social services comprised institutional centres (such as nursing homes and homes for people with a mental illness or a learning disability), day centres (for elderly people and people with a mental illness) and home services (such as the home help service for elderly people).

The health services comprised hospital facilities, such as: hospitals for chronically ill and long-stay patients; short-stay medical units located in acute hospitals; units for psychiatric hospitalisation providing intensive treatment under a continuous care regime in acute hospitals; outpatients' services such as units for mental health, which care for people with mental health problems who are referred from primary care; units for addictive behaviour; and units for home hospitalisation providing specialised healthcare at home after hospital discharge.

Spain, like other Mediterranean countries, is a familybased society (Esping-Andersen 2000), and a high percentage of the dependent population is cared for in their own homes. The estimated number of people who received social and healthcare in the Valencia Autonomous Region in 2001 was 115 136, or $48 \%$ of the population of people with dependant needs (Garcés et al. 2002). Of these, 37096 people used social services and 78040 used health services. Note that the present study assesses the needs of people who use services, and that comparable information about people who are deemed dependent but do not use services is lacking.

Multistage stratified random sampling was used to select users from specific services in each stratum (i.e. social and healthcare). The healthcare system and the social services system in Spain have different legislation and administration. A number was assigned to each individual service and to each user, and then this information was used to produce a computer-generated list of randomly selected points and units.

The intended sample size was 1300 users, 715 from health services and 585 from social services; and the actual sample size was 1265, 709 from health services and 556 from social services. The sampling fractions were $0.916 \%$ for healthcare and $1.577 \%$ for social care. The sample size is large enough to give a $95 \%$ confidence level for assessing fractions within $\pm 4.1 \%$ of an observed overall percentage for the social stratum and $\pm 3.7 \%$ for the healthcare stratum. The confidence intervals were based on fractions for subjects having a specific characteristic $(p)$, or not having it $(q=1-p)$. The present authors used $p=q=0.5$.
The Social and Health Care Needs Questionnaire (SHCNQ) was developed specifically for the present study, and comprised 119 questions, some of which were answered by the person with needs and others by the carer. Seven sections are covered by the SHCNQ, including: social and demographic data; clinical diagnosis and treatment; living environment; functioning using the Barthel test (Mahoney 1965) and the Frenchay test (Bond et al. 1992); cognitive state using a Spanish adaptation of the Mini-Mental State Examination by Folstein et al. (1975) carried out by Lobo et al. (1979); social support, such as the presence or absence of a carer, and whether or not the user lives alone; and the social and demographic, and attendance data of the carer.

The SHCNQ was tested on randomly selected samples of people who used the social services $(n=30)$ and healthcare $(n=30)$ located in a single health area. These research participants did not form part of the main study. The pilot test detected minor problems in 19 of the 119 questions, and these were amended accordingly to produce a refined version of the SHCNQ.

The quality of field work by the five interviewers was monitored and reviewed closely by: providing several training sessions for interviewers; having written standardised rules for completion of the SHCNQ interview; ongoing supervision of interviews, including cross-checking agreement between interviewers and a supervisor or independent researcher regarding the interpretation of verbal responses and their transfer to the questionnaire; and monitoring fieldwork via regular phone calls with interviewers, and weekly coordination meetings. Cronbach's alpha coefficients $(n=1265)$ indicated high internal reliability: Barthel test $=0.96$; Frenchay test $=0.89$; Lobo test $=0.79$; and living environment $=0.99$.

When it was not possible to interview the randomly selected candidate, the person with the number immediately next to the number of the first choice candidate was interviewed. A carer completed the SHCNQ when the relative could not answer directly because of poor health. The response rate was very high at $97 \%$. The non-respondents $(n=35)$ were those who were users of at-home services who were in poor health and without a carer $(n=6$, home hospitalisation), those who were not at home ( $n=8$, social resources) or those who refused to participate ( $n=21$, social resources).

\section{Results}

The main results of the present study are given below. The tables show estimated numbers in the population, and the figures observed in the sample are weighted accordingly: $37096 / 556=66.72$ for the social stratum, and $78040 / 709=110.07$ for the healthcare stratum. 


\section{Social and demographic data}

Table 1 shows that users of social services tended to be 3-4 years older on average than users of healthcare services. It also shows that there were more than twice as many female users in social services aged 65 years or over $(71.4 \%)$ than male users $(28.6 \%)$. Among those under 65 years, most users of social services were single $(63.6 \%)$, as were most users of healthcare (43.6\%). However, among those aged 65 years or over, the majority of social services users were widowed $(54.9 \%)$, while the majority of healthcare users were married (57.6\%). As regards education, the combination of being under 65 years of age and healthcare showed that $45.7 \%$ were educated to primary level and $24.8 \%$ to secondary level. In the other three combinations, most users had no education, with less than $10 \%$ being educated above primary level.

Table 2 gives a breakdown by gender and age of each type of facility studied. In social services, females tended to outnumber males except for centres for the chronic mentally ill (60.0\% male) and residential homes for the disabled $(59.1 \%$ male). In healthcare, units for mental health showed the largest percentage of females $(61.3 \%)$, while units for addictive conduct had the largest percentage of males (81.2\%).

\section{Dependence in activities of daily life}

Approximately $71.8 \%$ of healthcare users and $31.5 \%$ of social care users were independent in basic activities of daily living (BADLs) according to the Barthel test (Table 3). It is notable that at least twice as many social service users as healthcare users were mildly (33.4\% versus $12.7 \%)$, moderately (13.7\% versus $4.9 \%$ ) or severely (21.4\% versus $10.6 \%$ ) dependent for BADLs. Dependence in BADLs is, above all, associated with elderly people of both sexes.

Table 4 shows the breakdown according to the Frenchay test by strata, gender and age group. The great majority of social and healthcare users were moderately or severely dependent in instrumental activities of daily living (IADLs), i.e. $81.1 \%$ of healthcare users and $98.2 \%$ of social care users. Gender differences were not great. By age, there was a very high percentage of severe dependants in IADLs among people aged above 65 years $(73.0 \%)$. Among those under 65 years, most were moderately dependent $(55.0 \%)$.

Table 5 shows the breakdown according to the Lobo test by strata, gender and age group. More than two-thirds of healthcare users showed full cognitive ability $(70.1 \%)$, while the situation was the reverse for social care users, with almost two-thirds showing cognitive failure (64.9\%).

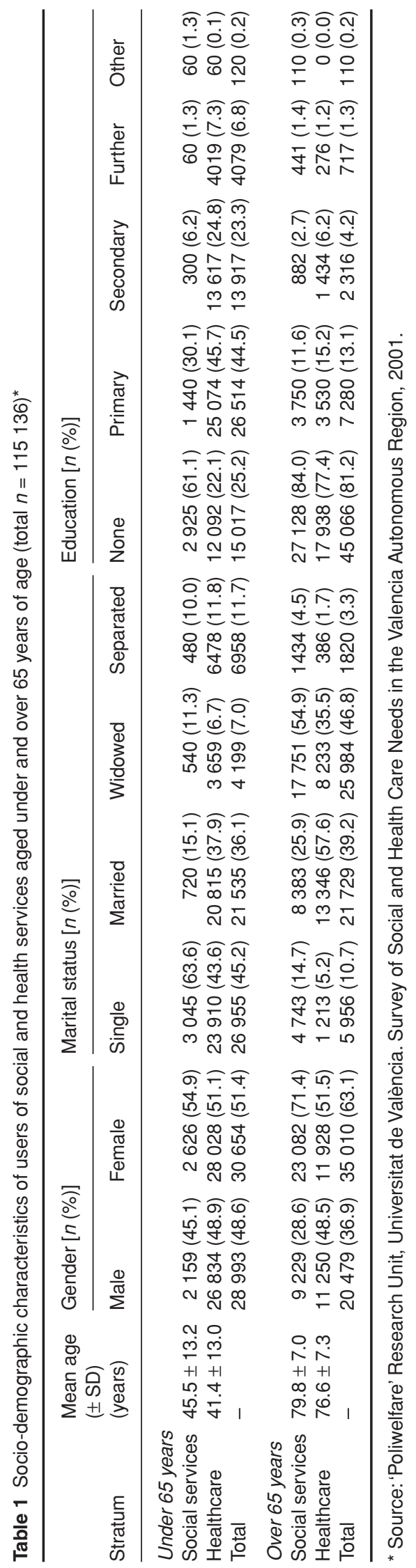


Table 2 Number of people by age and gender who use each type of facility or service (total $n=115136)^{*}$

\begin{tabular}{|c|c|c|c|c|c|c|}
\hline \multirow[b]{3}{*}{ Type of resource } & \multicolumn{6}{|l|}{ Gender } \\
\hline & \multicolumn{2}{|l|}{ Male } & \multicolumn{2}{|l|}{ Female } & \multicolumn{2}{|l|}{ Total } \\
\hline & Number (\%) & $\begin{array}{l}\text { Mean age } \\
( \pm S D) \text { (years) }\end{array}$ & Number (\%) & $\begin{array}{l}\text { Mean age } \\
( \pm \mathrm{SD}) \text { (years) }\end{array}$ & Number & $\begin{array}{l}\text { Mean age } \\
( \pm S D) \text { (years) }\end{array}$ \\
\hline \multicolumn{7}{|l|}{ Social services } \\
\hline Nursing home & $4686(34.4)$ & $76.5 \pm 9.2$ & $8929(65.6)$ & $80.0 \pm 8.0$ & 13615 & $78.8 \pm 8.6$ \\
\hline Specific centre for the chronic mentally ill & $48(60.0)$ & $38.2 \pm 5.6$ & $32(40.0)$ & $35.8 \pm 3.6$ & 80 & $37.2 \pm 5.1$ \\
\hline Residential home for the disabled & $625(59.1)$ & $40.7 \pm 10.4$ & $433(40.9)$ & $34.7 \pm 9.1$ & 1058 & $38.2 \pm 10.3$ \\
\hline $\begin{array}{l}\text { Centre for rehabilitation and social } \\
\text { integration of the chronic mentally ill }\end{array}$ & $141(46.7)$ & $36.1 \pm 8.5$ & $162(53.3)$ & $31.6 \pm 8.7$ & 303 & $33.7 \pm 8.9$ \\
\hline Day centre & $178(25.7)$ & $70.7 \pm 10.4$ & $514(74.3)$ & $78.0 \pm 6.6$ & 692 & $76.1 \pm 8.4$ \\
\hline Phone assistance & $650(11.6)$ & $79.2 \pm 9.5$ & $4935(88.4)$ & $74.6 \pm 10.0$ & 5585 & $75.1 \pm 10.0$ \\
\hline Home-help service & 3071 (30.7) & $65.7 \pm 21.4$ & 6935 (69.3) & $74.3 \pm 13.1$ & 10006 & $71.7 \pm 16.6$ \\
\hline Elderly care help & $1989(34.5)$ & $81.3 \pm 5.3$ & $3768(65.5)$ & $83.5 \pm 5.2$ & 5757 & $82.8 \pm 5.4$ \\
\hline Total & $11388(30.7)$ & $72.0 \pm 16.8$ & 25708 (69.3) & $76.8 \pm 12.3$ & 37096 & $75.3 \pm 14.1$ \\
\hline \multicolumn{7}{|l|}{ Healthcare } \\
\hline Short-stay medical units & $6389(52.3)$ & $68.8 \pm 17.5$ & $5818(47.7)$ & $66.0 \pm 20.0$ & 12207 & $67.5 \pm 18.8$ \\
\hline $\begin{array}{l}\text { Hospitals for chronically ill and } \\
\text { long-stay patient care }\end{array}$ & $2916(52.4)$ & $70.0 \pm 12.8$ & $2645(47.6)$ & $75.0 \pm 13.5$ & 5561 & $72.4 \pm 13.4$ \\
\hline Unit for psychiatric hospitalisation & $2270(47.7)$ & $37.8 \pm 12.5$ & $2489(52.3)$ & $39.3 \pm 13.9$ & 4759 & $38.6 \pm 13.2$ \\
\hline Unit for home hospitalisation & $3580(50.2)$ & $71.2 \pm 15.0$ & $3548(49.8)$ & $73.2 \pm 14.7$ & 7128 & $72.2 \pm 14.9$ \\
\hline Unit for mental health & $14880(38.7)$ & $41.2 \pm 13.0$ & $23587(61.3)$ & $49.0 \pm 15.9$ & 38467 & $46.0 \pm 15.3$ \\
\hline Units for addictive conduct & $8049(81.2)$ & $34.9 \pm 7.9$ & 1869 (18.8) & $33.9 \pm 9.0$ & 9918 & $34.7 \pm 8.2$ \\
\hline Total & $38084(48.8)$ & $49.4 \pm 19.9$ & $39956(51.2)$ & $54.15 \pm 19.6$ & 78040 & $51.9 \pm 19.9$ \\
\hline
\end{tabular}

* Source: 'Poliwelfare' Research Unit, Universitat de València. Survey of Social and Health Care Needs in the Valencia Autonomous Region, 2001.

Table 3 Levels of dependency as measured by the Barthel test (total $n=115136)^{*}$

\begin{tabular}{|c|c|c|c|c|c|}
\hline \multirow[b]{2}{*}{ Variable } & \multicolumn{4}{|c|}{ Level of dependence [n(\%)] } & \multirow[b]{2}{*}{ Total $(n)$} \\
\hline & Independent & $\begin{array}{l}\text { Slight } \\
\text { dependence }\end{array}$ & $\begin{array}{l}\text { Moderate } \\
\text { dependence }\end{array}$ & $\begin{array}{l}\text { Severe or total } \\
\text { dependence }\end{array}$ & \\
\hline \multicolumn{6}{|c|}{ Social services } \\
\hline \multicolumn{6}{|c|}{ Gender: } \\
\hline male & $4043(35.5)$ & 3672 (32.3) & $927(8.1)$ & $2746(24.1)$ & 11388 \\
\hline female & $7642(29.7)$ & 8718 (33.9) & 4155 (16.2) & $5193(20.2)$ & 25708 \\
\hline \multicolumn{6}{|c|}{ Age (years): } \\
\hline$<65$ & $2300(48.1)$ & $927(19.4)$ & $408(8.5)$ & $1150(24.0)$ & 4785 \\
\hline$\geq 65$ & $9385(29.0)$ & $11463(35.5)$ & $4674(14.5)$ & $6789(21.0)$ & 32311 \\
\hline Subtotal & 11685 (31.5) & $12390(33.4)$ & $5082(13.7)$ & $7939(21.4)$ & 37096 \\
\hline \multicolumn{6}{|c|}{ Healthcare } \\
\hline \multicolumn{6}{|l|}{ Gender: } \\
\hline male & $28094(73.8)$ & 3201 (8.4) & $2731(7.2)$ & $4058(10.6)$ & 38084 \\
\hline female & 27939 (69.9) & $6710(16.8)$ & $1093(2.7)$ & $4214(10.6)$ & 39956 \\
\hline \multicolumn{6}{|c|}{ Age (years): } \\
\hline$<65$ & 49555 (90.3) & $4059(7.4)$ & $312(0.6)$ & $936(1.7)$ & 54862 \\
\hline$\geq 65$ & 6478 (27.9) & $5852(25.2)$ & $3512(15.2)$ & $7336(31.7)$ & 23178 \\
\hline Subtotal & $56033(71.8)$ & $9911(12.7)$ & $3824(4.9)$ & $8272(10.6)$ & 78040 \\
\hline
\end{tabular}

${ }^{*}$ NB Range of Barthel scores: independent $=20$; slight dependence $=15-19$; moderate dependence $=10-14$; and severe or total dependence $=0-9$.

Source: 'Poliwelfare' Research Unit, Universitat de València. Survey of Social and Health Care Needs in the Valencia Autonomous Region, 2001. 
Table 4 Levels of dependency as measured by the Frenchay test (total $n=115136$ )*

\begin{tabular}{|c|c|c|c|c|c|}
\hline \multirow[b]{2}{*}{ Variable } & \multicolumn{4}{|c|}{ Level of dependence $[n(\%)]$} & \multirow[b]{2}{*}{ Total $(n)$} \\
\hline & Independent & $\begin{array}{l}\text { Slight } \\
\text { dependence }\end{array}$ & $\begin{array}{l}\text { Moderate } \\
\text { dependence }\end{array}$ & $\begin{array}{l}\text { Severe or total } \\
\text { dependence }\end{array}$ & \\
\hline \multicolumn{6}{|c|}{ Social services } \\
\hline \multicolumn{6}{|l|}{ Gender: } \\
\hline male & $0(0.0)$ & $0(0.0)$ & $2040(17.9)$ & $9348(82.1)$ & 11388 \\
\hline female & $0(0.0)$ & $667(2.6)$ & $6159(24.0)$ & $18882(73.4)$ & 25708 \\
\hline \multicolumn{6}{|c|}{ Age (years): } \\
\hline$<65$ & $0(0.0)$ & $482(10.1)$ & $1224(25.6)$ & 3079 (64.3) & 4785 \\
\hline$\geq 65$ & $0(0.0)$ & $185(0.6)$ & $6975(21.6)$ & $25151(77.8)$ & 32311 \\
\hline Subtotal & $0(0.0)$ & $667(1.8)$ & $8199(22.1)$ & $28230(76.1)$ & 37096 \\
\hline \multicolumn{6}{|c|}{ Healthcare } \\
\hline \multicolumn{6}{|c|}{ Gender: } \\
\hline male & $234(0.6)$ & $3668(9.6)$ & $17325(45.5)$ & $16857(44.3)$ & 38084 \\
\hline female & $156(0.4)$ & $10691(26.7)$ & $20212(50.6)$ & 8897 (22.3) & 39956 \\
\hline \multicolumn{6}{|c|}{ Age (years): } \\
\hline$<65$ & $390(0.7)$ & $12486(22.8)$ & $31606(57.6)$ & $10380(18.9)$ & 54862 \\
\hline$\geq 65$ & $0(0.0)$ & $1873(8.1)$ & $5931(25.6)$ & $15374(66.3)$ & 23178 \\
\hline Subtotal & $390(0.5)$ & $14359(18.4)$ & $37537(48.1)$ & $25754(33.0)$ & 78040 \\
\hline
\end{tabular}

* NB Range of Frenchay scores: independent $=60$; slight dependence $=45-59$; moderate dependence $=30-44$; severe or total dependence $=0-29$.

Source:'Poliwelfare' Research Unit, Universitat de València. Survey of Social and Health Care Needs in the Valencia Autonomous Region, 2001.

Table 5 Levels of dependency as measured by the Lobo test on cognitive state (total $n=115136)^{*}$

\begin{tabular}{|c|c|c|c|}
\hline \multirow[b]{2}{*}{ Variable } & \multicolumn{2}{|c|}{ Cognitive failure $[n(\%)]$} & \multirow[b]{2}{*}{ Total $(n)$} \\
\hline & No & Yes & \\
\hline \multicolumn{4}{|c|}{ Social services } \\
\hline \multicolumn{4}{|l|}{ Gender: } \\
\hline male & $4971(43.7)$ & $6417(56.4)$ & 11388 \\
\hline female & 8050 (31.3) & $17658(68.7)$ & 25708 \\
\hline \multicolumn{4}{|c|}{ Age (years): } \\
\hline$<65$ & $2597(54.3)$ & $2188(45.7)$ & 4785 \\
\hline$\geq 65$ & 10424 (32.3) & 21887 (67.7) & 32311 \\
\hline Subtotal & $13021(35.1)$ & 24075 (64.9) & 37096 \\
\hline \multicolumn{4}{|c|}{ Healthcare } \\
\hline \multicolumn{4}{|l|}{ Gender: } \\
\hline male & 29109 (76.4) & $8975(23.6)$ & 38084 \\
\hline female & $25597(64.1)$ & 14359 (35.9) & 39956 \\
\hline \multicolumn{4}{|c|}{ Age (years): } \\
\hline$<65$ & $47760(87.1)$ & $7102(12.9)$ & 54862 \\
\hline$\geq 65$ & $6946(30.0)$ & $16232(70.0)$ & 23178 \\
\hline Subtotal & $54706(70.1)$ & $23334(29.9)$ & 78040 \\
\hline
\end{tabular}

* NB Range of Lobo test scores: No cognitive failure: 28 or more; Cognitive failure: 27 or less.

Source: 'Poliwelfare' Research Unit, Universitat de València. Survey of Social and Health Care Needs in the Valencia Autonomous Region, 2001.

Amongst those over 65 years, the percentage of people with cognitive failure $(68.7 \%)$ was four times the percentage of those under $65(15.6 \%)$. Cognitive failure was mostly associated with women aged over
65 years, who represent half the social and healthcare users suffering this problem $(50.0 \%)$.

Table 6 shows the characteristic values of the three tests for each type of centre or service. Combining the results of the Barthel, Frenchay and Lobo tests provided an overview of the autonomy of each kind of user. This enabled the differentiation of those needing personal and continuous care and vigilance from others who need home help only.

\section{State of health}

Table 7 shows that mental disorders were very frequent in social and healthcare users aged under 65 years. Chronic illnesses were also very widespread, in particular among social care users $(84.6 \%)$, most of whom were elderly people with multiple illnesses. The other illness groups were much smaller and/or were related to users of very specific centres or services.

As regards the stage of the illness the patient was passing through at the time of the interview, more than $90 \%$ of social and healthcare users were under treatment for their condition, and only $2.5 \%$ were at the terminal stage.

Another interesting characteristic relating to state of health is clinical complexity, which the present authors defined according to the procedures which each patient was receiving (Box 1). Table 8 shows the number and percentage of people with different levels of clinical complexity in each type of facility or service. As expected, it 
Table 6 Characteristic levels for basic activities of daily living (BADLs), instrumental activities of daily living (IADLs) and cognitive state for each type of facility or service*

\begin{tabular}{|c|c|c|c|}
\hline Type of resource & $\begin{array}{l}\text { BADLs } \\
\text { (Barthel) }\end{array}$ & $\begin{array}{l}\text { IADLs } \\
\text { (Frenchay) }\end{array}$ & $\begin{array}{l}\text { Cognitive state } \\
\text { (Mini-Examen Cognoscitivo) }\end{array}$ \\
\hline Nursing home & Slight & Severe & Cognitive failure \\
\hline Specific centre for the chronic mentally ill & Independent & Severe & Cognitive conservation \\
\hline Residential home for the disabled & Independent/slight & Moderate & Cognitive failure \\
\hline $\begin{array}{l}\text { Centre for rehabilitation and social } \\
\text { integration of the chronic mentally ill }\end{array}$ & Independent & Moderate & Cognitive conservation \\
\hline Day centre & Severe & Severe & Cognitive failure \\
\hline Phone assistance & Independent & Moderate & Cognitive conservation/failure \\
\hline Home-help service & Slight & Severe & Cognitive failure \\
\hline Elderly care help & Slight & Severe & Cognitive failure \\
\hline Short-term-stay medical units & Independent & Slight/Moderate/Severe & Cognitive conservation \\
\hline $\begin{array}{l}\text { Hospitals for chronically ill and } \\
\text { long-stay patient care }\end{array}$ & Severe & Severe & Cognitive failure \\
\hline Unit for psychiatric hospitalisation & Independent & Moderate & Cognitive conservation \\
\hline Unit for home hospitalisation & Slight & Severe & Cognitive conservation/failure \\
\hline Unit for mental health & Independent & Moderate & Cognitive conservation \\
\hline Units for addictive conduct & Independent & Moderate & Cognitive conservation \\
\hline
\end{tabular}

* NB In facilities or services where more than one category appears in a test, the groups defined by these categories are very similar in their percentages.

Source:'Poliwelfare' Research Unit, Universitat de València. Survey of Social and Health Care Needs in the Valencia Autonomous Region, 2001.

Box 1 Clinical complexity*

Patient needs

Enteral or parenteral feeding, assisted breathing or respiratory therapy - chest drain or transfusion.

Fluid therapy, respiratory or functional physiotherapy, chemotherapy, radiotherapy, biopsy, complex cures, ostomy or tracheotomy care, blood analysis, dialysis, or psychotherapy.

None of the above, but perhaps oxygen treatment or medication.
Clinical complexity

High

Medium

Low

* Source: 'Poliwelfare' Research Unit, Universitat de València, 2002.

was amongst healthcare users that there was a greater proportion of patients with high $(72.4 \%)$ and medium (7.8\%) clinical complexity.

\section{Social support}

For the purposes of the present study, a suitable home carer was considered to be a person aged under 75 years, either present or mentioned by the dependent person interviewed, who either belonged to the patient's nuclear family or had been employed to care for the patient for the necessary time, or at least for 6 months, at the patient's home or that of the carer. In the population studied, $71.0 \%$ of healthcare users, but only $39.1 \%$ of social care users, had a suitable carer.

\section{Discussion}

The present study shows that the characteristic profiles of social and healthcare patients in the Valencia
Autonomous Region, a typical southern European Mediterranean area, were the following:

- Social care users: A widow aged, on average, 77 years, uneducated, receiving a widow's pension, cared for at home or in a home for elderly people, and suffering multiple chronic illnesses for which active treatment is being received.

- Healthcare users: A man or woman aged, on average, 52 years, single or married, with primary education, working or disabled for work, suffering chronic mental or multiple illnesses for which active treatment is being received.

Care needs are different for men and women. Many more women use at-home and community resources, such as day centres, phone assistance, the home-help service and aid for the elderly. This seems to show that they can remain at home longer than men, perhaps because they have greater autonomy in basic domestic 
Table 7 Number of people suffering illness for each type of facility or service*

\begin{tabular}{|c|c|c|c|c|c|c|c|}
\hline \multirow[b]{2}{*}{ Type of resource } & \multicolumn{7}{|c|}{ Type of illness [ $n(\%)]$} \\
\hline & $\begin{array}{l}\text { Mental } \\
\text { disorder }\end{array}$ & $\begin{array}{l}\text { Chronic } \\
\text { illness }\end{array}$ & $\begin{array}{l}\text { Acute } \\
\text { illness }\end{array}$ & $\begin{array}{l}\text { Degenerative } \\
\text { illness }\end{array}$ & $\begin{array}{l}\text { Cancer-related } \\
\text { illness }\end{array}$ & HIV/AIDS & $\begin{array}{l}\text { Congenital } \\
\text { illness }\end{array}$ \\
\hline \multicolumn{8}{|l|}{ Social services } \\
\hline Nursing home & $5160(37.9)$ & 12322 (90.5) & $3540(26.0)$ & $4370(32.1)$ & $831(6.1)$ & $0(0.0)$ & $0(0.0)$ \\
\hline $\begin{array}{l}\text { Specific centre for the chronic } \\
\text { mentally ill }\end{array}$ & $80(100.0)$ & $32(40.0)$ & $16(20.0)$ & $0(0.0)$ & $8(10.0)$ & $16(20.0)$ & $0(0.0)$ \\
\hline Residential home for the disabled & $1058(100.0)$ & $432(40.8)$ & $48(4.5)$ & $0(0.0)$ & $0(0.0)$ & $0(0.0)$ & $48(4.5)$ \\
\hline $\begin{array}{l}\text { Centre for rehabilitation and social } \\
\text { integration of the chronic mentally ill }\end{array}$ & $303(100.0)$ & $80(26.4)$ & $10(3.3)$ & $0(0.0)$ & $0(0.0)$ & $0(0.0)$ & $0(0.0)$ \\
\hline Day centre & $580(83.8)$ & $620(89.6)$ & $180(26.0)$ & $340(49.1)$ & $20(2.9)$ & $0(0.0)$ & $20(2.9)$ \\
\hline Phone assistance & $519(9.3)$ & $4680(83.8)$ & $1173(21.0)$ & $910(16.3)$ & $128(2.3)$ & $0(0.0)$ & $0(0.0)$ \\
\hline Home-help service & $2822(28.2)$ & $8225(82.2)$ & $1171(11.7)$ & $2001(20.0)$ & $590(5.9)$ & $0(0.0)$ & $350(3.5)$ \\
\hline Elderly care help & 1681 (29.2) & $4934(85.7)$ & $524(9.1)$ & $628(10.9)$ & $104(1.8)$ & $0(0.0)$ & $0(0.0)$ \\
\hline Subtotal & $12242(33.0)$ & $31383(84.6)$ & $6714(18.1)$ & $8272(22.3)$ & $1669(4.5)$ & $0(0.0)$ & $408(1.1)$ \\
\hline \multicolumn{8}{|l|}{ Healthcare } \\
\hline Short-term-stay medical units & $1831(15.0)$ & $7190(58.9)$ & $7532(61.7)$ & $793(6.5)$ & $2173(17.8)$ & $0(0.0)$ & $110(0.9)$ \\
\hline $\begin{array}{l}\text { Hospitals for chronically ill and } \\
\text { long-stay patient care }\end{array}$ & $1168(21.0)$ & $5188(93.3)$ & $1563(28.1)$ & $1318(23.7)$ & $751(13.5)$ & $61(1.1)$ & $28(0.5)$ \\
\hline Unit for psychiatric hospitalisation & $4759(100.0)$ & $1018(21.4)$ & $657(13.8)$ & $0(0.0)$ & $0(0.0)$ & $71(1.5)$ & $0(0.0)$ \\
\hline Unit for home hospitalisation & $1055(14.8)$ & $5988(84.0)$ & $3650(51.2)$ & $798(11.2)$ & 2466 (34.6) & $64(0.9)$ & $36(0.5)$ \\
\hline Unit for mental health & $38467(100.0)$ & $9309(24.2)$ & $3731(9.7)$ & $2500(6.5)$ & $615(1.6)$ & $0(0.0)$ & $0(0.0)$ \\
\hline Unit for addictive conduct & 9759 (98.4) & $7032(70.9)$ & $426(4.3)$ & $149(1.5)$ & $0(0.0)$ & $2440(24.6)$ & $149(1.5)$ \\
\hline Subtotal & $56813(72.8)$ & $35898(46.0)$ & $17715(22.7)$ & $5619(7.2)$ & $6087(7.8)$ & $2653(3.4)$ & $312(0.4)$ \\
\hline Total & $69312(60.2)$ & $67124(58.3)$ & 24409 (21.2) & $13816(12.0)$ & $7829(6.8)$ & 2648 (2.3) & $691(0.6)$ \\
\hline
\end{tabular}

* Source: 'Poliwelfare' Research Unit, Universitat de València. Survey of Social and Health Care Needs in the Valencia Autonomous Region, 2001. 
Table 8 Breakdown of clinical complexity for each type of facility or service (total $n=115136$ )*

\begin{tabular}{|c|c|c|c|c|}
\hline \multirow[b]{2}{*}{ Type of resource } & \multicolumn{3}{|c|}{ Clinical complexity } & \multirow[b]{2}{*}{ Total } \\
\hline & Low & Medium & High & \\
\hline \multicolumn{5}{|l|}{ Social services } \\
\hline Nursing home & $7897(58.0)$ & $5623(41.3)$ & $95(0.7)$ & 13615 \\
\hline Specific centre for the chronic mentally ill & $0(0.0)$ & $80(100.0)$ & $0(0.0)$ & 80 \\
\hline Residential home for the disabled & $1009(95.4)$ & $49(4.6)$ & $0(0.0)$ & 1058 \\
\hline $\begin{array}{l}\text { Centre for rehabilitation and social integration } \\
\text { of the chronic mentally ill }\end{array}$ & $121(40.0)$ & $182(60.0)$ & $0(0.0)$ & 303 \\
\hline Day centre & $277(40.0)$ & $415(60.0)$ & $0(0.0)$ & 692 \\
\hline Phone assistance & $4675(83.7)$ & $782(14.0)$ & $128(2.3)$ & 5585 \\
\hline Home-help service & $7645(76.4)$ & $2121(21.2)$ & $240(2.4)$ & 10006 \\
\hline Elderly care help & $5440(94.5)$ & $317(5.5)$ & $0(0.0)$ & 5757 \\
\hline Total & $27064(73.0)$ & $9569(25.8)$ & $463(1.2)$ & 37096 \\
\hline \multicolumn{5}{|l|}{ Healthcare } \\
\hline Short-term-stay medical units & $1489(12.2)$ & 8203 (67.2) & $2515(20.6)$ & 12207 \\
\hline $\begin{array}{l}\text { Hospitals for chronically ill and long-stay } \\
\text { patient care }\end{array}$ & $1713(30.8)$ & $2525(45.4)$ & $1323(23.8)$ & 5561 \\
\hline Unit for psychiatric hospitalisation & $1832(38.5)$ & $2855(60.0)$ & $72(1.5)$ & 4759 \\
\hline Unit for home hospitalisation & $870(12.2)$ & $4227(59.3)$ & $2031(28.5)$ & 7128 \\
\hline Unit for mental health & $8694(22.6)$ & $29773(77.4)$ & $0(0.0)$ & 38467 \\
\hline Units for addictive conduct & $863(8.7)$ & $8906(89.8)$ & $149(1.5)$ & 9918 \\
\hline Total & $15461(19.8)$ & $56489(72.4)$ & $6090(7.8)$ & 78040 \\
\hline
\end{tabular}

* Source:'Poliwelfare' Research Unit, Universitat de València. Survey of Social and Health Care Needs in the Valencia Autonomous Region, 2001.

tasks and receive greater social support. Nevertheless, at younger ages, there are more women than men using units for mental health, evidencing a greater demand for care for slight mental disorders (neuroses) among women, either because of a greater incidence of this type of illness among women or a lower level of resistance in acknowledging its existence by men. The situation is the other way round amongst users of units for addictive conduct, most of whom are men.

As regards dependence on another person, the great majority of the social and healthcare population show slight dependence in BADLs, but are more dependent in IADLs. This is the basic characteristic of the survey population: dependence in IADLs of $98 \%$ and $81 \%$ amongst social care and healthcare users, respectively.

The highest degree of severe dependency is to be found in the group aged 65 years and over, especially among users of social resources for the elderly (e.g. nursing homes and day centres), and in the healthcare stratum, among patients using home hospitalisation services and those in hospitals for chronic patients.

Cognitive failure is another source of dependence on others. This problem is fundamentally associated with elderly people, especially in women aged over 65 years, who represent over half the people suffering from this problem in the survey population.
Analysis of state of health indicates that mental and/ or chronic disorders together affected virtually everyone in the survey population. The large, and growing, numbers of young people using resources for the mentally ill indicate their special care needs. In fact, the mean ages of users in units of mental heath and units for psychiatric hospitalisation are less than 40 and 50 years, respectively. If such patients are not supported by their families, then they require very long-term care.

Chronic illnesses mainly affect people over 65 years of age who tend to suffer multiple illnesses. In many cases, these patients can be treated at home if a suitable carer and resources are available.

The great majority of social and healthcare users are in the active therapy stage, with fairly low levels of clinical complexity amongst social care users and average levels amongst healthcare users. This suggests the possibility of referring healthcare patients from hospitals to home nursing care in the more complex cases, or to outpatient services in combination with home social care in less complex ones. The present authors are currently studying this possibility for enhancing system efficiency and will shortly offer their results.

If patients are to have reasonable quality of life in care outside hospitals, they must have social and family support, and in cases of dependence or fragile health, a carer is required. In the population studied, the present 
authors found a lack of sufficient carers for $60.9 \%$ of social services users. This poses a problem for the implementation of alternative care scenarios at home.

Most of the survey population aged under 65 years (54 862 out of a total of 59647 ) receive healthcare services. A high percentage of them have a mental illness and/or drug-related illness. Such pathologies reduce their independence for IADLs, but do not affect BADLs (except in the case of terminal patients). They can be treated in the short and medium term in specific out-patient healthcare facilities.

Social facilities serve more than half of those aged above 65 years (32 311 out of a total of 55489 ). Most of these individuals receive active treatment for many chronic illnesses and are dependent for IADLs. Most of their needs can be met by home and/or community services.

If the needs of this group are not met, the demand for institutional facilities increases. Many of these patients could remain in their own homes if:

- the home was adapted and the relevant technical aids were installed;

- carer training programmes were carried out, offering professional, trained staff to patients lacking a carer; and

- family carer aid programmes were extended (e.g. with carer substitution, rest periods and psychological support).

In this way, many requests for institutionalisation and the high risk of family carer rejection could be avoided. Social and health services could then focus on home and community services, which are much cheaper and more satisfactory from the point of view of users' quality of life.

The present report has been used in the debate on an appropriate social and healthcare policy to meet the specific needs of the dependent population, and on new administrative structures for this purpose, such as a Valencian Agency for Dependent People.

\section{Acknowledgements}

The research presented in this paper received finance from the Ministry for Science and Technology, through the Spanish National R + D + I Plan (2000-2003), and from the Generalitat Valenciana, Conselleria de Sanidad, 2001-2002.

\section{References}

Bond M.J., Harris R.D., Smith D.S. \& Clark M.S. (1992) An examination of the factor structure of the Frenchay Activities Index. Disability and Rehabilitation 1 (14), 27-29.

Bonoli G., George V. \& Taylor-Gooby P. (2000) European Welfare Futures. Polity Press, Cambridge.

Directorate-General for Economic and Financial Affairs (2002a) Incorporating the sustainability of public finances into the Stability and Growth Pact. European Economy 3, 62-74.

Directorate-General for Economic and Financial Affairs (2002b) The long-term sustainability of public finances. European Economy 3, 32-36.

Economic Policy Committee (2001) Budgetary Challenges Posed by Ageing Populations. ECOFIN /655/ 01-EN, November. European Commission, Brussels.

Economic Policy Committee (2002) Reform Challenges Facing Public Pension Systems: The Impact of Certain Parametric Reforms on Pensions Expenditure. ECOFIN /237/ 02-final, July. European Commission, Brussels.

Esping-Andersen G. (2000) Fundamentos Sociales de Las Economías Postindustriales. Ariel, Barcelona.

Folstein M.F., Folstein S.E. \& McHugh P.R. (1975) Mini-Mental State. A practical method for grading the cognitive state of patients for the clinician. Journal of Psychiatric Research 12 (3), 189-198.

Garcés J. (2000) La Nueva Sostenibilidad Social. Ariel, Barcelona.

Garcés J., Ródenas F., Megía M.J. \& Zafra E. (2002) Estudio Sobre Demanda y Necesidades de Asistencia Sociosanitaria en la Comunidad Valenciana 2000-2001. Generalitat Valenciana, Valencia.

Gustafsson B.A. \& Klevmarken N.A. (1989) The Political Economy of Social Security. North-Holland, Amsterdam.

Instituto de Migraciones y Servicios Sociales (2000) La Protección Social de la Dependencia. Ministerio de Trabajo y Asuntos Sociales, Madrid.

Kautto M., Fritzell J., Hvinden B., Kvist J. \& Uusitalo H. (Eds) (2001) Nordic Welfare States in the European Context. Routledge, London.

Lobo A., Gómez Burgada F., Sala J.M. \& Seva Díaz A. (1979) El Mini-Examen Cognoscitivo en pacientes geriátricos. Folia Neuropsiquiátrica 14, 244-251.

Mahoney F.I. \& Barthel D.W. (1965) Functional evaluation: the Barthel Index. Maryland State Medical Journal 14, 61-65.

Munday B. (Ed.) (1993) European Social Services. European Institute of Social Services (EISS), University of Kent, Canterbury.

Munday B. \& Ely P. (1996) Social Care in Europe. Prentice Hall, Harvester Wheatsheaf, London.

Organisation for Economic Co-operation and Development (1996) Pay Reform in the Public Service: Initial Impact on Pay Dispersion in Australia, Sweden and the United Kingdom. Organisation for Economic Co-operation and Development, Paris.

Organisation for Economic Co-operation and Development (1998) The Caring World. An Analysis. DEELSA/ELSA/MIN 98, 3. Organisation for Economic Co-operation and Development, Paris. 